\title{
STUDY OF OCULAR TRAUMA PATTERN IN A TERTIARY CARE HOSPITAL IN RURAL AREA OF INDIA
}

\author{
Eknath Shelke1, Mahesh Sonpethkar², Bhaskar Khaire3, Pramod Deosarkar ${ }^{4}$ \\ ${ }^{1}$ Assistant Professor, Department of Ophthalmology, SRTR GMC, Ambajogai. \\ ${ }^{2}$ Senior Resident, Department of Ophthalmology, SRTR GMC, Ambajogai. \\ 3 Professor, Department of Ophthalmology, SRTR GMC, Ambajogai. \\ ${ }^{4}$ Postgraduate Student, Department of Ophthalmology, SRTR GMC, Ambajogai.
}

\section{ABSTRACT}

\section{BACKGROUND}

Ocular trauma is an important public health hazard.

The objective of this study was to determine pattern of ocular trauma among the patients presenting in a rural medical college of India.

\section{MATERIALS AND METHODS}

One year retrospective review of records of 150 patients with Ocular trauma presenting to OPD of rural medical college from 1 st August 2015 to $31^{\text {st }}$ July 2016 was done using a structured format. Association between variables were checked using chi square test and significance was considered when $\mathrm{p}$ value was $<0.05$.

\section{RESULTS}

Out of 14,286 patients seen during this period in OPD and emergency, ocular trauma accounted in 150 (1.05\%) patients. Out of 150 patients, 93 (62\%) patients were below 30 years of age. M:F ratio was 2.7:1. 32 (21.33\%) patients presented within 24 hours from the time of injury whereas 37 (24.66\%) presented in 2-7 days of injury. Duration of presentation has significant association with presence of infection and other complications $(\mathrm{P}<0.05)$. Commonest cause of injury was road traffic accidents $63(42 \%)$, followed by sports and recreational activities 49 (33\%), occupational 30 (20\%) and miscellaneous $8(5 \%)$. Open globe injury accounted for 68 (45.33\%), and closed globe injury for 47 (31.33\%) and adnexal injury constituted 35 (23.33\%). Presentation delay was associated with more complications.

\section{CONCLUSION}

Ocular trauma being an important health hazard should get a prompt attention in emergency department to avoid complications. There should be a mass education regarding the hazardous effects and complications of ocular trauma and also regarding the safety measures to prevent it.

\section{KEYWORDS}

Ocular Trauma, Open Globe Injury, Closed Globe Injury, Blindness.

HOW TO CITE THIS ARTICLE: Shelke E, Sonpethkar M, Khaire B, et al. Study of ocular trauma pattern in a tertiary care hospital in rural area of India. J. Evolution Med. Dent. Sci. 2016;5(99):7284-7287, DOI: 10.14260/jemds/2016/1648

\section{BACKGROUND}

One of the leading cause of visual morbidity and blindness is trauma to the eye and its surrounding structure. Many ocular traumas are an avoidable cause of blindness and visual impairment. ${ }^{1}$

Worldwide there are approximately 6 million people blind due to eye injuries, 2.3 million bilaterally visually impaired and 19 million with unilateral visual loss; these facts make ocular trauma the most common cause of unilateral blindness. ${ }^{2}$ Serious ocular trauma has bimodal age distribution with maximum evidence in young adults and second peak in elderly. ${ }^{3,4}$

Financial or Other, Competing Interest: None.

Submission 07-11-2016, Peer Review 01-12-2016,

Acceptance 07-12-2016, Published 12-12-2016.

Corresponding Author:

Dr. Eknath Shelke,

Assistant Professor,

Department of Ophthalmology,

SRTR GMC Ambajogai,

Beed-431517, Maharashtra.

E-mail: ebshelke35@gmail.com

DOI: $10.14260 /$ jemds $/ 2016 / 1648$

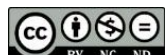

According to WHO estimates, about 55 million eye injuries, restricting activities for more than one day occur each year, 750,000 cases requiring hospitalisation which include 2,00,000 open globe injuries. ${ }^{5}$

Worldwide, male to female ratio was found to be $4: 1.6,7,8$. and open globe injury is said to be more common. $9,10,11,12$

Ocular injuries can assume unusual social and economic importance involving a huge cost in human unhappiness, economic insufficiency and monetary loss.

In view of public health importance as no studies had been carried out on patterns of ocular trauma in study area, this study will provide information on magnitude and pattern of ocular injuries in rural area of Maharashtra, India and will serve as the basis for designing and implementing preventive measures to be undertaken by respective authorities.

\section{MATERIALS AND METHODS}

A one year retrospective study was conducted in department of Ophthalmology, in a tertiary care hospital, in rural area of Maharashtra, India from $1^{\text {st }}$ August 2015 to 31 ${ }^{\text {st }}$ July 2016.

Ocular trauma accounted for 150 (1.05\%) of 14,286 Ocular patients seen in OPD and emergency during above-mentioned one year period. All patients with ocular trauma were selected for the study. Data was collected from clinical records using 
structured format. Collected data was edited, checked for completeness and cross checked for accuracy to ensure the quality and was analysed using SPSS for windows version 16.0. Associations between variables were checked by chi-square test and significance was considered when $\mathrm{P}<0.05$. All records of patients were kept confidential.

Operational Definitions were according to World Health Organization (WHO) and Birmingham Eye Trauma Terminology System (BETTS). ${ }^{6}$

\section{Blindness}

Visual acuity $<3 / 60$.

\section{Eye Wall}

Cornea and sclera.

\section{Open Globe Injury}

Full thickness wound of eye wall.

\section{Laceration}

Full thickness wound at impact site of a sharp object by outside mechanism.

\section{Lamellar Laceration}

Partial thickness wound at impact site of a sharp object by outside mechanism.

\section{Penetration}

Has entrance wound only.

\section{Perforation}

Has entrance as well as exit wound.

\section{Rupture}

Full-thickness wound by blunt object by inside out mechanism due to increased intraocular pressure.

\section{Intraocular Foreign Body}

Is technically a penetrating injury but grouped separately because of its clinical implications.

\section{Adnexal Injuries}

Eyelids and/or conjunctival injuries.

\section{RESULTS}

Out of 14,286 ocular patients seen in OPD and emergency from time period $1^{\text {st }}$ August 2015 to $31^{\text {st }}$ July 2016, ocular trauma accounted in $150(1.05 \%)$ patients. Amongst 150 cases, 93 (62\%) patients were below 30 years with mean age of 28.8 (SD +/- 17.1) years. Male to female ratio was 2.7: 1 (Table 1)

In our study, $32(21.33 \%)$ patients presented within 24 hours of injury, $37(24.66 \%)$ presented in 1-7 days, 38 (25.33\%) presented in 8-30 days, 43 (28.66\%) presented after 1 month.

Right eye was involved in 67 (45\%) patients, left eye was involved in 83 (55\%) patients. Amongst the causes of injury, road traffic accidents accounted maximum number of cases i.e., 63 (42\%), followed by sports and recreational activities 49 (33\%), occupation related 33 (20\%) and miscellaneous 8 (5\%) which includes domestic accidents, violence related etc. (Table 2)
Regarding the object of injury, the commonest material causing trauma was stone 33 (22\%) followed by wooden piece $20(13 \%)$, iron rod 18 (12\%); other miscellaneous modes of injury include fist injury, thorn injury, metal wire, cricket ball, etc.

Amongst the injuries, open globe injuries were found to be more common accounting for 68 (45.33\%) patients compared to closed globe injuries accounting for 47 (31.33\%) patients and adnexal injuries accounting for 35 (23.33\%) patients. Complications like traumatic cataract, hyphaema, raised intraocular pressure, hypopyon, endophthalmitis were present in $64(42.66 \%)$ patients. Out of these, only 48 (32\%) patients presented within 24 hours. Presence of complications was found to have significant association with the duration of presentation ( $\mathrm{P}$ value 0.001 ).

On evaluating visual acuity at presentation, $48(32 \%)$ had visual acuity of $6 / 6$ to $6 / 18$ while $84(56 \%)$ patients were blind at presentation i.e. their visual acuity was less than $3 / 60$. $21(14 \%)$ patients had NPL visual acuity at presentation.

Final visual outcome (Considered 2 weeks after treatment) was difficult to analyse in $16(10.66 \%)$ cases, and was not documented in $6(4 \%)$ cases as patients were not co-operative. Out of remaining 128 patients, 56 (37.33\%) cases had visual outcome 6/6-6/18, whereas blinding outcome was noted in 49 $(32.66 \%)$ patients in spite of best operative procedures and management available (Table 3).

\section{DISCUSSION}

In our study, we found the magnitude of ocular trauma to be $1.05 \%$ out of total ocular patients seen in out patients department and emergency, which is significantly lower as compared to JUDO study, South West Ethiopia where it was found to be $6.9 \% .12$

In our study, we found $93(62 \%)$ patients were below the age of 30 years with mean age of 28.8 (SD+/-17.1) years with male to female ratio $2.7: 1$.

Whereas study done at JUDO found $63.8 \%$ patients were below the age of $30 \mathrm{yrs}$. with mean age 25.5 (SD+/-15.6) years and male to female ratio of 3.2:1.

In our study, $21.33 \%$ patients presented within 24 hours, $24.66 \%$ presented in 1-7 days, $25.33 \%$ presented within $8-30$ days while $28.66 \%$ presented after 1 month; whereas in JUDO Study $31.6 \%$ patients presented in 48 hours, and $28.6 \%$ presented at one week or later. 12

In our study, right eye was involved in $45 \%$ cases whereas left eye was involved in 55\% cases. This didn't show significant association between the involvement of either eye. But the slight predominance of left eye injuries may be explained by the facts that most people are right handed and left eye of the victim is the one which is more vulnerable to an attack from right-handed person.

Considering the cause of injury, road traffic accidents occurred for maximum number of cases i.e. 63 (42\%) followed by sports and recreational activities in 49 (33\%) patients, miscellaneous causes like domestic accidents, violence related were found in $8(5 \%)$ patients.

JUDO study showed injuries by violence related causes to be the most common cause i.e. $37.2 \% .^{12}$

In JUDO Study of the documented ones, wood was the commonest material in $40.9 \%$ cases followed by metal in $18.1 \%$ and stone in $13.3 \%$ cases. In our study, we found stone being the commonest material for injury in $33(22 \%)$ cases 
followed by wooden piece in 20 (13\%) cases, iron rod in 18 (12\%) cases.

On considering the type of injury in our study, we found open globe injury accounting for $45.33 \%$ compared to closed globe injury which accounted for $31.33 \%$. Whereas in JUDO Study it showed closed globe injuries (45.4\%) were encountered more than open globe injuries $(22.71 \%){ }^{12}$

In our study, we found a significant association between the duration of presentation and presence of complications at presentation (Chi- square value 18.2, degree of freedom $=3$, $p$. value $=0.001$ ) which may affect final visual outcome. Two weeks after the treatment, the final visual outcome was analysed which was difficult to analyse in $16(10.66 \%)$ cases and was not documented in $6(4 \%)$ cases as they were not cooperative.

Out of the remaining 128 cases, 56 (37.33\%) cases had visual outcome of $6 / 6$ to $6 / 18$, whereas $49(32.66 \%)$ patients were documented to have blinding outcome.

JUDO Study showed $21.1 \%$ of ocular injuries had blinding outcome i.e. visual acuity $<3 / 60$.

A study conducted in Haryana showed males (76.01\%) were more frequently affected than females (23.99\%). In Nonoccupational injuries (61.74\%), those occurring due to playing and sports among children were the main aetiological factors (33.67\%) whereas in occupational injuries (38.26\%) those occurring during agricultural activities (19.9\%) were most common followed by industrial accidents (12.24\%). ${ }^{13}$

Comparison of our study with the data from some other studies was difficult in some aspect because of different definitions, classifications and methods of reporting used in these studies. But still it is possible to conclude from this study that delay in presentation has a significant association with presence of complications which may have a detrimental visual outcome.

Our study also showed that road traffic accidents are the commonest cause of the ocular injuries followed by sports and occupational accidents. So advocating preventive measures by health workers to emphasise the importance of early health seeking behaviour and followup of patients with ocular trauma is recommended. Simple safety procedure like wearing seat belts while driving, using protective glasses in industries, supervising children while playing, etc. should be advocated through public education using mass media.

Also, our hospitals should design an urgent referral system for emergency care services for ocular trauma patients. We should have proper documentation system by designing structured and standardised format for treating and following up the ocular trauma patients which in turn will help in doing more researches in fundamental area and planning its emergency care services.

\begin{tabular}{|c|c|c|c|}
\hline Age (Yrs.) & Male & Female & Total \\
\hline $0-10$ & 24 & 12 & 36 \\
\hline $11-20$ & 23 & 07 & 30 \\
\hline $21-30$ & 23 & 04 & 27 \\
\hline $31-40$ & 20 & 06 & 26 \\
\hline $41-50$ & 06 & 03 & 09 \\
\hline $51-60$ & 06 & 03 & 09 \\
\hline$>60$ & 08 & 05 & 13 \\
\hline Total Table 1. Age Group and Sex Distribution \\
of Ocular Trauma Patients \\
\hline
\end{tabular}

\begin{tabular}{|c|c|c|c|}
\hline Cause of Injury & Male & Female & Total \\
\hline $\begin{array}{c}\text { Road Traffic } \\
\text { Accidents }\end{array}$ & 50 & 13 & 63 \\
\hline $\begin{array}{c}\text { Sports \& Recreational } \\
\text { Activities }\end{array}$ & 30 & 19 & 49 \\
\hline Occupation Related & 25 & 05 & 30 \\
\hline Miscellaneous & 05 & 03 & 08 \\
\hline Total & 110 & 40 & 150 \\
\hline $\begin{array}{c}\text { Table 2. Cause of Injury and Sex } \\
\text { Distribution in Ocular Trauma Cases }\end{array}$ \\
\hline
\end{tabular}

\begin{tabular}{|c|c|c|c|c|c|c|}
\hline \multirow{2}{*}{ Type of Injury } & \multicolumn{5}{|c|}{ Final Visual Outcome } & \multirow{2}{*}{ Total } \\
\hline & 6/6-6/18 & $<6 / 18-3 / 60$ & $<3 / 60-$ NPL & Not Documented & Not Co Operative & \\
\hline \multicolumn{7}{|l|}{ Closed Globe Injury } \\
\hline Lamellar Laceration & $05(3.33 \%)$ & $2(1.33 \%)$ & $1(0.66 \%)$ & $2(1.33 \%)$ & $2(1.33 \%)$ & $12(8 \%)$ \\
\hline Contusion & $22(14.66 \%)$ & $4(2.66 \%)$ & $2(1.33 \%)$ & $7(4.66 \%)$ & 0 & $35(23.33 \%)$ \\
\hline \multicolumn{7}{|l|}{ Open Globe Injury } \\
\hline Penetrating Injury & 0 & $10(6.66 \%)$ & $43(28.66 \%)$ & $7(4.66 \%)$ & $2(1.33 \%)$ & $62(41.33 \%)$ \\
\hline $\begin{array}{l}\text { Perforating } \\
\text { Injury }\end{array}$ & 0 & 0 & $1(0.66 \%)$ & 0 & 0 & $1(0.66 \%)$ \\
\hline IOFB & $1(0.66 \%)$ & $2(1.33 \%)$ & $2(1.33 \%)$ & 0 & 0 & $5(3.33 \%)$ \\
\hline Rupture & 0 & 0 & 0 & 0 & 0 & 0 \\
\hline Adnexal & $28(18.66 \%)$ & $5(3.33 \%)$ & 0 & 0 & $2(1.33 \%)$ & $35(23.33 \%)$ \\
\hline Total & $56(37.35 \%)$ & $23(15.33 \%)$ & $49(32.66 \%)$ & $16(10.66 \%)$ & $6(4 \%)$ & 150 \\
\hline \multicolumn{7}{|c|}{ Table 3. Type of Injury and Final Visual Outcome } \\
\hline
\end{tabular}

\begin{tabular}{|c|c|}
\hline Duration & Number of Patients \\
\hline 0-24 hrs. & $32(21.33 \%)$ \\
\hline 1-7 days & $37(24.66 \%)$ \\
\hline 8-30 days & $38(25.33 \%)$ \\
\hline >1 Month & $43(28.66 \%)$ \\
\hline \multicolumn{2}{|c|}{$\begin{array}{c}\text { Table 4. Duration between Onset } \\
\text { of Injury and Attending Hospital }\end{array}$} \\
\hline
\end{tabular}

\section{CONCLUSION}

Ocular trauma is an important health factor. Most of the patients who presented to us are young and a male predominance is noted. Road traffic accidents are the commonest cause of the ocular injuries followed by sports and occupational accidents. Also there is significant association between duration of presentation and presence of infection. 
Presentation delay is associated with more complications. So advocating preventive measures by health workers to emphasise the importance of early health seeking behaviour and followup of patients with ocular trauma is recommended. Simple safety procedure like wearing seat belts while driving, using protective glasses in industries, supervising children while playing, etc. should be advocated through public education using mass media. There should be a proper documentation system by designing structured and standardised format for treating and following up the ocular trauma patients which in turn will help in doing more researches in fundamental area and planning its emergency care services.

\section{REFERENCES}

1. Omolase CO, Omolade EO, Ogunleye OT, et al. Pattern of ocular injuries in Owo, Nigeria. J Ophthalmic Vis Res 2011;6(2):114-8.

2. Negrel AD, Thylefors B. The global impact of eye injuries. Ophthalmic Epidemiology 1998;5(3):143-69.

3. Glynn RJ, Seddon JM, Berlin BM. The incidence of eye injuries in New England adults. Arch Ophthalmology 1988;106(6):785-9.

4. Desai P, MacEwen CJ, Baines P, et al. Epidemiology and implications of ocular trauma admitted to hospital in Scotland. J Epidemiology Comm Health 1996;50(4):43641.
5. Khan MD, Mohammad S, Islam ZU, et al. An 11 years review of ocular trauma in the northwest frontier province of Pakistan. Pak J Ophthalmology 1991;7:15-8.

6. Kuhn F. Epidemiology of ocular trauma. In: Kuhn F, Morris $\mathrm{R}$, Mester V, et al, eds. Ocular traumatology. SpringerVerlag Berlin Heidelberg 2005:47-77.

7. Framme C, Roider J. Epidemiology of open globe injuries. Klin Monatsbl Augenheik 1999;215:287-93.

8. Casson RJ, Walker JC, Newland HS. 4-year review of open eye injuries at the Royal Adelaide Hospital. Clin Exp Ophthalmol 2002;30(1):15-8.

9. Gyasi ME, Amoaku WMK, Adjuik MA. Epidemiology of hospitalized ocular injuries in the upper east region of Ghana. Ghana Medical Journal 2007;41(4):171-5.

10. Serrano J, Chalela P, Arias JD. Epidemiology of childhood ocular trauma in north-eastern Colombian region. Arch Ophthalmol 2003;121(10):1439-45.

11. Woo JH, Sundar G. Eye injuries in Singapore-don"t risk it. Do more. A prospective study. Ann Acad Med Singapore 2006;35(10):706-718.

12. Asaminew T, Gelaw Y, Alemseged F. A 2-year review of ocular trauma in Jimma University specialized hospital. Ethiop J Health Sciences 2009;19(2):67-76.

13. Parmar IPS, Sunandan S, Nagpal RC. Pattern of ocular injuries in Haryana. Ind J Ophthalmol 1985;33(3):141-44. 